\title{
Nickel-Catalyzed C-CN Bond Formation via Decarbonylative Cyanation of Esters, Amides and Intramolecular Recombination Fragment Coupling of Acyl Cyanides
}

\author{
Adisak Chatupheeraphat, ${ }^{\dagger, \S}$ Hsuan-Hung Liao, ${ }^{\dagger, \S}$ Shao-Chi Lee ${ }^{\dagger}$ and Magnus Rueping*, ${ }^{*,+}$ \\ † Institute of Organic Chemistry, RWTH Aachen University, Landoltweg 1, 52074 Aachen, Germany \\ ${ }^{\ddagger}$ King Abdullah University of Science and Technology (KAUST), KAUST Catalysis Center (KCC), Thuwal 23955- \\ 690o, Saudi Arabia
}

ABSTRACT: An efficient nickel catalyzed decarbonylative cyanation reaction which allows the direct functional-group interconversion of readily available esters into the corresponding nitriles was developed. This reaction successfully offers access to structurally diverse nitriles with high efficiency, excellent functional-group tolerance, and provides a good alternative to classical synthetic pathways from diazonium salts or organic halide compounds.

The development of transition metal catalyzed crosscoupling reactions has emerged as a powerful method for carbon-carbon bond formations. Recently, an increasing emphasis on environmentally friendly approaches has stimulated research aimed at finding lower toxicity and economical cross-coupling partners, which avoid the corrosive halide-containing waste production in transition metal catalyzed reactions. Particular attention has been drawn to the use of carboxylic acid derivatives, such as esters and amides in decarbonylative transformations, ${ }^{1,2}$ to further complement organic halides as coupling partners. Commonly, aromatic and unsaturated as well as saturated aliphatic rests have been introduced on (hetero)aromatic substrates, leading to a wide range of new $\mathrm{C}-\mathrm{C}$ bond forming reactions (Scheme 1 , left). In contrast, less is known regarding the direct introduction of C-based functional groups on (hetero)aromatic substrates. With these considerations in mind we decided to target the $\mathrm{C}-\mathrm{CN}$ bond formation via a decarbonylative transformation (Scheme 1, right).

Scheme 1. Decarbonylative transformations: C-C bond formations

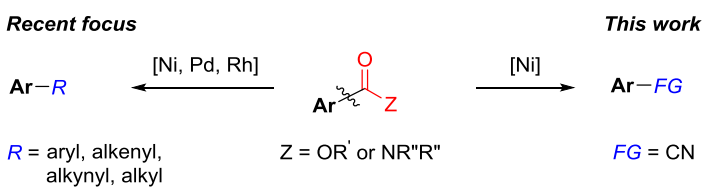

Nitriles are important structural motifs in pharmaceutically relevant molecules and electronic materials. ${ }^{3}$ In addition, the nitrile moiety can be used as an intermediate for a multitude of transformations ${ }^{4}$ (Scheme S1). Traditionally, the introduction of the cyano group into aromatic compounds was achieved by Sandmeyer and Rosenmund von Braun reactions. However, the relatively limited substrate scope of these reactions led chemists to explore alternative ways involving metal catalyzed conversions of aryl (pseudo) halides into more diversely substituted aromatic nitriles. ${ }^{5}$ In order to accomplish our goal and develop a first ester to cyanide functional group interconversion, we needed to overcome several challenges: 1) the strongly binding cyanide anions may deactivate and poison the catalyst; 2 ) the propensity of acyl cyanide formation instead of desired nitrile product; ${ }^{6} 3$ ) nitrile product decomposition due to the lack of chemoselectivity ${ }^{7}$ (Scheme S2).

We herein describe a significant advance in the realm of nickel catalyzed decarbonylative reactions which successfully suppressed the deleterious side reactions mentioned above and provides a new method for the formation of $\mathrm{C}\left(\mathrm{sp}^{2}\right)-\mathrm{CN}$ bonds. Guided by our previous reaction development in the area of functional group interconversions, ${ }^{8}$ survey coupling experiments with phenyl 2-naphthoate (1a) under $\mathrm{Ni}(\operatorname{cod})_{2}$ catalysis were carried out. From the different cyanide reagents available, use of zinc cyanide (2a) provided a successful decarbonylative introduction of the $\mathrm{CN}$ group. Further experiments were conducted with a series of trialkylmonodentate phosphine ligands, including $\mathrm{P}^{n} \mathrm{Bu}_{3}$ and $\mathrm{PCy}_{3}$ which resulted only in a low yield of the desired nitrile product 3a (Table 1, entries 1-2). Carbene ligands such as 1,3-bis(2,6-diisopropylphenyl) imidazolidin-2ylidene (SIPr) did not provide the product (Table 1 , entry 3). Further evaluation of bidentate phosphine complexes revealed a beneficial effect in terms of reactivity (Table 1 , entries 4 and 5). The best ligand was identified as dcype [1,2-bis (dicyclohexylphosphino) ethane] providing the product in $72 \%$ yield (Table 1 , entry 5 ). Next, further bases were tested in order to reach higher yield (Table 1, entries 6 and 7 ) and the best result was obtained with $\mathrm{HCO}_{2} \mathrm{Na}$ (Table 1, entry 7). A decrease in the yield of the product was observed when the reaction was performed in the absence of base (Table 1, entry 8). Further optimization focused on other solvents; switching the solvent from 
toluene to $\mathrm{iPr}_{2} \mathrm{O}$ and dioxane did not provide a better yield (Table, entries 9 and 10). Next, the influence of the amount of ligand was examined and changing the ratio of catalyst/ligand from 1:2 to 1:1 reduced the yield of the product to $37 \%$ (Table 1, entry 11). Reducing the amount of zinc cyanide (o.6 equiv) still provided an excellent yield (Table 1, entry 12). Lastly, control experiments showed that no desired product was formed in the absence of nickel catalyst and ligand (Table 1, entries 13 and 14).

Table 1. Optimization of the nickel catalyzed decarbonylatvie cyanation coupling reaction. ${ }^{a}$

\begin{tabular}{|c|c|c|c|c|}
\hline & & \multicolumn{2}{|r|}{$\begin{array}{l}\mathrm{Ni}(\operatorname{cod})_{2}(10 \mathrm{~mol} \%) \\
\text { ligand }(20 \mathrm{~mol} \%)\end{array}$} & \multirow[t]{2}{*}{$\mathrm{N}^{\mathrm{Cn}}$} \\
\hline & 1a & 2 & $\begin{array}{l}\text { base (2 equiv) } \\
\text { solvent, } 150^{\circ} \mathrm{C}, 48 \mathrm{~h}\end{array}$ & \\
\hline entry & ligand & base & solvent & yield $^{b}(\%)$ \\
\hline 1 & $\mathrm{P}_{n} \mathrm{Bu}_{3}$ & $\mathrm{Cs}_{2} \mathrm{CO}_{3}$ & Toluene & 33 \\
\hline 2 & $\mathrm{PC}_{3}$ & $\mathrm{Cs}_{2} \mathrm{CO}_{3}$ & Toluene & 31 \\
\hline 3 & SIPr & $\mathrm{Cs}_{2} \mathrm{CO}_{3}$ & toluene & - \\
\hline 4 & dcype & $\mathrm{Cs}_{2} \mathrm{CO}_{3}$ & toluene & 72 \\
\hline 5 & dcypb & $\mathrm{Cs}_{2} \mathrm{CO}_{3}$ & toluene & 34 \\
\hline 6 & dcype & $\mathrm{CsCl}$ & toluene & 82 \\
\hline 7 & dcype & $\mathrm{HCO}_{2} \mathrm{Na}$ & toluene & 89 \\
\hline 8 & dcype & - & toluene & 50 \\
\hline 9 & dcype & $\mathrm{HCO}_{2} \mathrm{Na}$ & $\mathrm{iPr}_{2} \mathrm{O}$ & 72 \\
\hline 10 & dcype & $\mathrm{HCO}_{2} \mathrm{Na}$ & dioxane & 84 \\
\hline $11^{c}$ & dcype & $\mathrm{HCO}_{2} \mathrm{Na}$ & toluene & 37 \\
\hline $12^{d}$ & dcype & $\mathrm{HCO}_{2} \mathrm{Na}$ & toluene & $94(90)^{e}$ \\
\hline $13^{d, f}$ & dcype & $\mathrm{HCO}_{2} \mathrm{Na}$ & toluene & - \\
\hline $14^{d}$ & - & $\mathrm{HCO}_{2} \mathrm{Na}$ & toluene & - \\
\hline
\end{tabular}

${ }^{a}$ Reaction conditions: $1 \mathbf{a}(0.3 \mathrm{mmol}), \mathbf{2}(\mathrm{o} .6 \mathrm{mmol})$, solvent (1 ml)., $150^{\circ} \mathrm{C}, 48 \mathrm{~h} .{ }^{b} \mathrm{NMR}$ yield, $1,3,5-(\mathrm{OMe})_{3} \mathrm{C}_{6} \mathrm{H}_{3}$ as internal standard. ${ }^{\circ}$ Using dcype (1o mol \%). ${ }^{d}$ Using $\mathrm{ZnCN}_{2}$ (o.2 mmol).

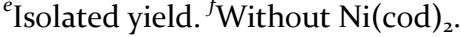

With the optimized conditions in hand, we studied the scope of this newly developed nickel catalyzed decarbonylative cyanation of esters with zinc cyanide. As revealed in Scheme 2, a variety of aromatic esters with different electronic properties and substitution patterns provided the corresponding nitriles $3 \mathbf{a}-\mathbf{m}$ with moderate to high yields. Notably, the reaction is chemoselective; use of substrate $\mathbf{1 m}$ bearing a methyl and a phenyl ester group provided $3 \mathbf{m}$ in $71 \%$ yield. Lastly, esters incorporating a series of different heterocyclic patterns, including thiophene, indole and pyridine, were tested and adducts 3n-p were isolated with high yields. Importantly, our results demonstrate that the reaction is not limited to reactive and $\pi$-extended aromatic rings. ${ }^{9} \alpha, \beta$-Unsaturated nitriles, especially cinnamonitriles, are important synthons for further chemical transformations. ${ }^{10}$ Conventionally, the most straightforward approach towards their synthesis is the transition metal catalyzed cyanation of styrenyl halides. However, some procedures involve toxic metal cyanides and lack general applicability. More significantly, none of these reactions are stereoselective and produce a mixture of cis and trans-stereoisomers in varying amounts. ${ }^{11} \mathrm{We}$, therefore, have probed our developed system for the construction of versatile alkenyl nitriles. To our delight, a series of different esters which contain different electronic properties as well as $\beta$-substituted alkene reacted nicely to furnish the desired products 3q-t with high yields.

Scheme 2. The scope of nickel catalyzed cyanation cross-coupling with aryl and cinnamoyl esters. ${ }^{a, b}$

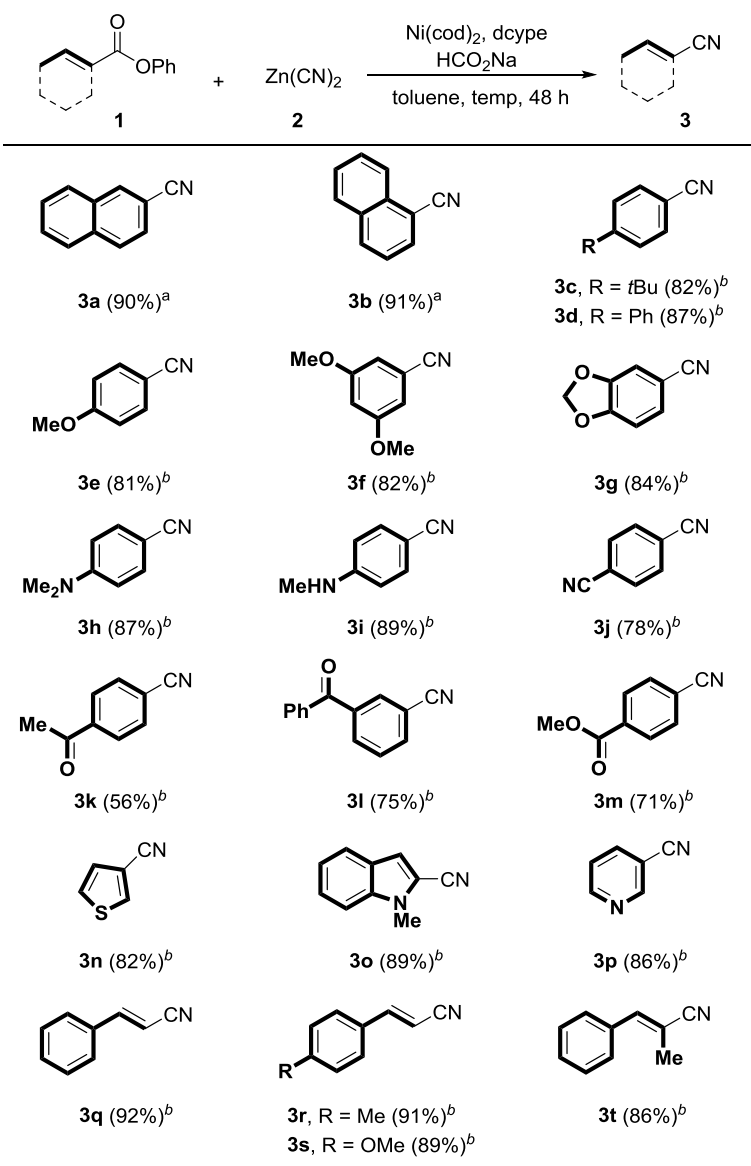

${ }^{a}$ Reaction conditions: 1 (o.2 mmol), $\mathrm{Zn}(\mathrm{CN})_{2}(0.16 \mathrm{mmol})$, $\mathrm{Ni}(\operatorname{cod})_{2}$ (10 mol \%), dcype (2o mol \%), $\mathrm{HCO}_{2} \mathrm{Na}$ (2 equiv), toluene (o.2 M), $150{ }^{\circ} \mathrm{C} 48$ h. ${ }^{b}$ At $170{ }^{\circ} \mathrm{C}$. Yields for isolated products za-t.

To further demonstrate the flexibility of the present approach for nitrile construction, the $\mathrm{C}-\mathrm{CN}$ bond formation with amides was investigated. ${ }^{2,12}$ We were delighted to see that the deamidative cyanation proceeded also smoothly and the products $5 \mathbf{a}-\mathbf{l}$ were obtained in good to high yields (Scheme 2).

Both being new procedures, the nickel catalyzed decarbonylative cyanation of esters as well as deamidative cyanation of amides provided a variety of alkenyl and aryl cyanides in good yields starting from readily available substrates. However, in both procedures byproducts in form of the phenol and gluatarimide, respectively, are formed. This can be prevented if a substrate in which the $\mathrm{CN}$ nucleophile is already incorporated could be applied. Thus, we wondered whether the corresponding acyl cyanides could be applied in a $\mathrm{CO}$ extrusion recombination fragment coupling strategy. A further 
improvement would be if nickel (II) salts could be applied in this intramolecular cyanation process. ${ }^{13}$ After intensive evaluation of the reaction parameters and application of a series of nickel(II) catalysts, we found $\mathrm{NiBr}_{2} \cdot 2$ methoxyethyl ether as optimal catalyst in terms of reactivity. ${ }^{14}$ To further demonstrate the generality of this protocol, a series of simple and activation site-free substrates has been applied into this extrusion recombination fragment coupling. ${ }^{15}$

Scheme 3. Scope of nickel catalyzed deamidative cyanation of amides. ${ }^{a}$

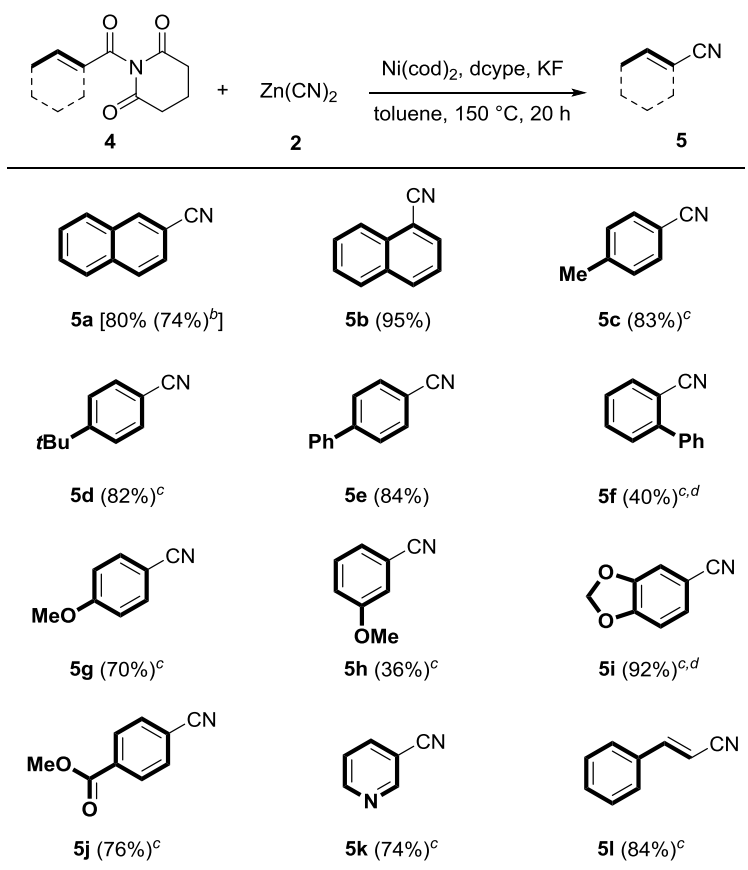

${ }^{a}$ Reaction conditions: 4 (o.2 mmol), $\mathrm{Zn}(\mathrm{CN})_{2}$ (0.4 mmol), $\mathrm{Ni}(\mathrm{cod})_{2}(10 \mathrm{~mol} \%)$, dcype (20 mol \%), KF (2 equiv), toluene (o.2 M), $150{ }^{\circ} \mathrm{C}, 20$ h. ${ }^{b}$ Reaction conditions: 4a $(3.74 \mathrm{mmol}$, $1 \mathrm{~g}), \mathrm{Zn}(\mathrm{CN})_{2}(7.48 \mathrm{mmol}), \mathrm{Ni}(\text { acac })_{2}$ (10 mol \%), dcype (20 mol \%), KF (2 equiv), toluene (o.2 M), under $\mathrm{MW} \mathrm{180}{ }^{\circ} \mathrm{C}, 6 \mathrm{~h}$. ${ }^{c}$ At $170^{\circ} \mathrm{C} .{ }^{d} 40 \mathrm{~h}$.

We were pleased to see that aromatic as well as heteroaromatic substrates $\mathbf{6 a}-\mathbf{h}$ were converted into the corresponding products in good to high yields (Scheme 4). A scale-up reaction with 1 gram of acyl cyanide $\mathbf{6 c}$ was carried out in order to demonstrate the scalability of our newly developed methodology and provided the nitrile product $\mathbf{7 c}$ in good yield (83\%). Notably, para-ketone substituted acyl cyanide $\mathbf{6 d}$ was successfully converted into nitrile $\mathbf{7 d}$ without decarbonylation of ketone as recently reported, ${ }^{16}$ which preserves the ketone group for further transformations. Lastly, the conjugate acyl cyanide system $\mathbf{6} \mathbf{i}$ gives cinnamonitrile $\mathbf{7} \mathbf{i}$ in high yield.

Furthermore, in order to create an easier manipulation of the intramolecular decarbonylative setting, we have designed a protocol for the direct preparation of nitriles from acyl chlorides without purification of acyl cyanide intermediate (Scheme 5). For this purpose, 2-naphthoyl chloride (8) was reacted with a stoichiometric amount of copper cyanide and then the crude product was filtrated over celite prior to the decarbonylative step. The desired 2-naphthoyl cyanide $\mathbf{7 j}$ was obtained in $7 \mathbf{2} \%$ overall yield.

Finaly, the power of this methodology is exemplified through its application to the synthesis of cyanostilbenes (Scheme 6), which due to their $\pi$-conjugated luminophores can be applied to optical device materials.

Scheme 4. The scope of nickel catalyzed acyl cyanide intramolecular decarbonylative cyanation reaction.

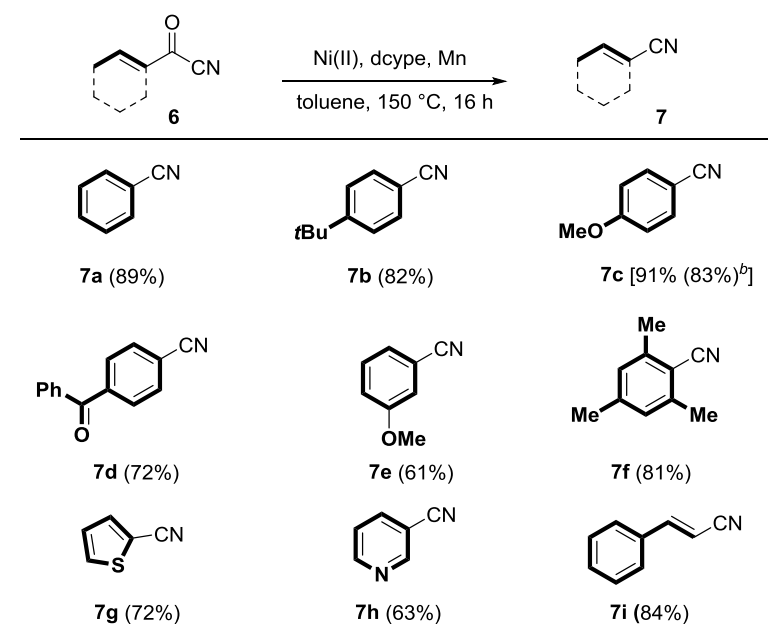

${ }^{a}$ Reaction conditions: 6 ( $\left.0.2 \mathrm{mmol}\right), \mathrm{NiBr}_{2} \cdot 2$-methoxyethyl ether (10 $\mathrm{mol} \%$ ), dcype ( $20 \mathrm{~mol} \%)$, Mn act as reducing agent of $\mathrm{Ni}$ (II) salt (2 equiv), toluene (o.2 M), $150{ }^{\circ} \mathrm{C}, 16 \mathrm{~h} .{ }^{b}$ Reaction on $1 \mathrm{~g}$ scale: $6 \mathrm{c}(6.2 \mathrm{mmol})$.

Scheme 5. Nickel catalyzed acyl cyanide intramolecular decarbonylative reaction in sequential reactions.

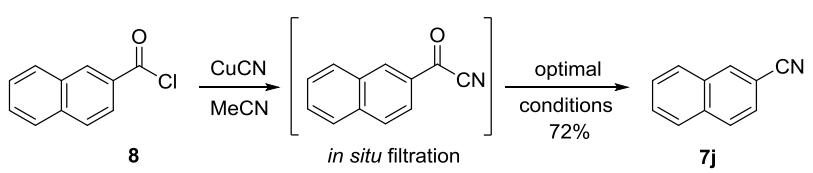

Reaction conditions: 1) 8 (o.4 mmol), $\mathrm{CuCN}$ (2 equiv), $\mathrm{MeCN}$ (o.4 M). 2) $\mathrm{NiBr}_{2} \cdot 2$-methoxyethyl ether (10 mol \%), dcype (20 mol \%), Mn act as reducing agent of $\mathrm{Ni}(\mathrm{II})$ salt (2 equiv), toluene $(0.2 \mathrm{M}), 150^{\circ} \mathrm{C}, 16 \mathrm{~h}$.

Scheme 6. Site-selective sequential decarboxylationdecarbonylation reaction.

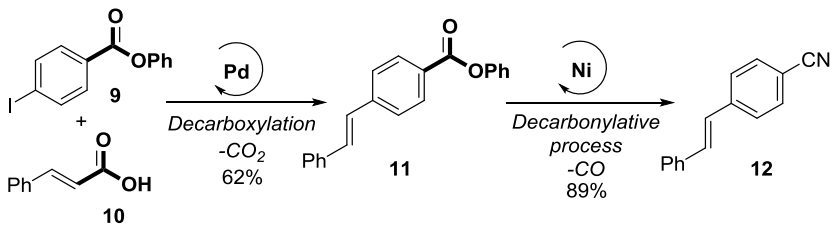

Reaction conditions: 1) 9 (1.2 mmol), cinnamic acid 10 (1.0 mmol), $\mathrm{PdBr}_{2}$ (o.03 mmol), $\mathrm{CuBr}$ (o.1 mmol) 1,10phenanthroline (o.1 mmol), $\mathrm{K}_{2} \mathrm{CO}_{3}(1 \mathrm{mmol}), 3 \AA \mathrm{MS}(250$ $\mathrm{mg})$, NMP (1.5 mL), quinoline (0.5 mL), $150{ }^{\circ} \mathrm{C}$. 2) 11 (0.2 $\mathrm{mmol}), \mathrm{Zn}(\mathrm{CN})_{2}$ (o.16 mmol), $\mathrm{HCO}_{2} \mathrm{Na}(0.4 \mathrm{mmol}), \mathrm{Ni}(\mathrm{cod})_{2}$ (10 mol \%), dcype (20 mol \%), toluene (o.2 M), $170{ }^{\circ} \mathrm{C} 48 \mathrm{~h}$.

In the first step we have exploited the molecular recognition properties and chemoselectivity of palladiumcatalyzed decarboxylative coupling ${ }^{17}$ of phenyl 4- 
iodobenzodate 9 with cinnamic acid 10 as coupling partner to provide the corresponding stilbene ester $\mathbf{1 1}$ in satisfactory yield $(62 \%)$. In the second step, the phenyl ester moiety underwent decarbonylative cyanation reaction leading to cyanostilbene $\mathbf{1 2}$ in $89 \%$ yield. We herein paved the way for a new synthetic route for the synthesis of a demanding compound under a sequential decarboxylation-decarbonylation manipulation.

In summary, we have developed the first nickel catalyzed decarbonylative cyanation protocol which allows the transfer of a series of readily available aryl and heteroaryl esters as well as amides to the corresponding nitriles. This protocol provides a new possibility to cleave carboxylic esters and amides while forming a $\mathrm{C}-\mathrm{CN}$ bond. The newly developed protocols successfully suppress the undesired acyl cyanide formation, nitrile product decomposition and catalyst posioning processes. In order to prevent byproduct formation, a nickel(II)-catalyzed extrusion recombination fragment coupling strategy allows direct access to aryl, heteroaryl and cinnamonitriles starting from the corresponding acyl cyanides. The new methods are characterized by high efficiency, chemoselectivity, and excellent functional group tolerance, providing a practical and versatile approach to a wide range of aryl and heteroaryl nitriles.

\section{ASSOCIATED CONTENT}

Supporting Information. Detailed experimental procedures, spectral data for all compounds, and copies of ${ }^{1} \mathrm{H}$ and ${ }^{13} \mathrm{C}$ spectra. This material is available free of charge via the Internet at http://pubs.acs.org.

\section{AUTHOR INFORMATION}

\section{Corresponding Author}

* magnus.rueping@kaust.edu.sa

\section{Author Contributions}

$\S$ These authors contributed equally to this work. Notes

The authors declare no competing financial interests.

\section{REFERENCES}

(1) (a) Gooßen, L. J.; Paetzold, J. Angew. Chem. Int. Ed. 20o2, 41, 1237. (b) Gooßen, L. J.; Paetzold, J. Angew. Chem. Int. Ed. 2004, 43, 1095. (c) Gribkov, D. V.; Pastine, S. J.; Schnürch, M.; Sames, D. J. Am. Chem. Soc. 2007, 129, 11750. (d) Muto, K.; Hatakeyama, T.; Itami, K.; Yamaguchi, Org. Lett. 2016, 18, 5106. (e) Okita, T.; Kumazawa, K.; Takise, R.; Muto, K.; Itami, K.; Yamaguchi, J. Chem. Lett. 2017, 46, 218. For examples of Ni-catalyzed decarbonylative transformations of esters for $\mathrm{C}-\mathrm{C}$ bond formations, see: (f) Amaike, K.; Muto, K.; Yamaguchi, J.; Itami, K. J. Am. Chem. Soc. 2012, 134, 13573. (g) Correa, A.; Cornella J.; Martin, R. Angew. Chem. Int. Ed. 2013, 52, 1878. (h) Meng, L.; Kamada, Y.; Muto, K.; Yamaguchi, J.; Itami, K. Angew. Chem., Int. Ed. 2013, 52, 10048. (i) Hong, X.; Liang, Y.; Houk, K. N. J. Am. Chem. Soc. 2014, 136, 2017. (j) Lu, Q.; Yu, H.; Fu, Y. J. Am. Chem. Soc. 2014, 136, 8252. (k) Muto, K.; Yamaguchi, J.; Musaev, D. G.; Itami, K.; Nat. Commun. 2015, 6, 7508. (l) Desnoyer, A. N.; Friese, F. W.; Chiu, W.; Drover, M. W.; Patrick, B. O.; Love, J. A. Chem. Eur. J. 2016, 22, 4070. (m) Amaike, K.; Itami, K.; Yamaguchi, J. Chem.-Eur. J. 2016, 22, 4384. (n) Takise, R.; Isshiki, R.; Muto, K.;
Itami, K.; Yamaguchi, J. J. Am. Chem. Soc. 2017, 139, 3340. (o) Liu, X.; Jia, J.; Rueping, M. ACS Catal. 2017, 7, 4491. For borylation and silylation, see: (p) Guo, L.; Chatupheeraphat, A.; Rueping, M. Angew. Chem. Int. Ed. 2016, 55, 11810. (q) Pu, X.; Hu, J.; Zhao, Y.; Shi, Z. ACS Catal. 2o16, 6, 6692. (r) Guo, L.; Rueping, M. Chem. Eur. J. 2016, 22, 16787. For amination, see: (e) Yue, H.; Guo, L.; Liao, H.-H.; Cai, Y.; Zhu, C.; Rueping, M. Angew. Chem. Int. Ed. 2017, 56, 4282 .

(2) Reviews: (a) Meng, G.; Shi, S.; Szostak, M. Synlett 2016, 27, 2530. (b) Dander, J. E.; Garg, N. K. ACS Cat. 2017, 7, 1413. (c) Liu, C.; Szostak, M. Chem. Eur. J. 2017, 23, 7157. Ni-catalyzed decarbonylative C-C bond formations from amides, see: (d) Shi, S.; Meng, G.; Szostak, M. Angew. Chem., Int. Ed. 2016, 55, 6959. (e) Srimontree, W.; Chatupheeraphat, A.; Liao, H.-H.; Rueping, M. Org. Lett. 2017, 19, 3091. For borylation and reduction, see: (f) Hu, J.; Zhao, Y.; Liu, J.; Zhang, Y.; Shi, Z. Angew. Chem., Int. Ed. 2016, 55, 8718. (g) Dey, A.; Sasmal, S.; Seth, K.; Lahiri, G. K.; Maiti, D. ACS Catal. 2o17, 7, 433. (h) Yue, H.; Guo, L.; Lee, S.-C.; Liu, X.; Rueping, M. Angew. Chem. Int. Ed. 2017, 56, 3972. (i) Hu, J.; Wang, M.; Pu, X.; Shi, Z. Nat. Commun. 2017, 8, 14993. (j) B. J. Simmons, M. Hoffmann, J. Hwang, M. K. Jackl, N. K. Garg, Org. Lett. 2017, 19, 1910. For examples of $\mathrm{Pd}$ and Rh-catalyzed decarbonylative transformations of amides, see: (k) Meng, G.; Szostak, M. Angew. Chem., Int. Ed. 2015, 54, 14518. (l) Liu, C.; Meng, G.; Szostak, M. J. Org. Chem. 2016, 81, 12023. (m) Meng, G.; Szostak, M. Org. Lett. 2016, 18, 796. (n) Wu, H.; Liu, T.; Cui, M.; Li, Y.; Jian, J.; Wang, H.; Zeng, Z. Org. Biomol. Chem. 2017, 15, 536. During the preparation of this manuscript, Szostak reported a related Pd-catalyzed decarbonylative cyanation of amides, see: (o) Shi, S.; Szostak, M. Org. Lett. 2017, 19, 3095.

(3) (a) Kleemann, A.; Engel, J.; Kutscher, B.; Reichert, D.; Pharmaceutical substances: syntheses, patents, applications, 4 th ed.; Georg Thieme: Stuttgart, 2001.

(4) (a) Rappoport, Z. Chemistry of the Cyano Group; John Wiley \& Sons: London, 1970. (b) Larcok, R. C. Comprehensive Organic Transformations; VCH: New York, 1989; Vol. 819.

(5) (a) Brandsma, L.; Vasilevsky, S. E.; Verkruijsse, H. D.; Application of Transition Metal Catalysts in Organic Synthesis; Springer-Verlag: Berlin: Heidelberg, 1998. (b) Ellis, G. P.; RomneyAlexander, T. M. Chem. Rev. 1987, 87, 779. (c) Anbarasan, P.; Schareina, T.; Beller, M. Chem. Soc. Rev. 2011, 40, 5049. Nicatalyzed cyanation of phenol derivatives, see: (d) Takise, R.; Itami, K.; Yamaguchi, J. Org. Lett. 2016, 18, 4428.

(6) A mixture of decarbonylative and ketone product was obtained in previous studies, see: (a) Gooßen, L. J.; Paetzold, J. Adv. Synth. Catal. 2004, 346, 1665. (b) LaBerge, N. A.; Love, J. A. Eur. J. Org. Chem. 2015, 5546.

(7) (a) Li, T.; Garcia, J. J.; Brennessel, W. W.; Jones, W. D.; Organometallics, 2010, 29, 2430. (b) Nakao, Y. Top. Curr. Chem. 2014, 346, 33. (c) Miscione, G. P.; Bottoni, A. Organometallics 2014, 33, 4173 .

(8) (a) Leiendecker, M.; Hsiao, C. C.; Guo, L.; Alandini, N.; Rueping, M. Angew. Chem. Int. Ed. 2014, 53, 12912. (b) Guo, L.; Leiendecker, M.; Hsiao, C.-C.; Baumann, C.; Rueping, M. Chem. Commun. 2015, 51, 1937. (c) Leiendecker, M.; Chatupheeraphat, A.; Rueping, M. Org. Chem. Front. 2015, 2, 350. (d) Liu, X.; Hsiao, C.-C.; Kalvet, I.; Leiendecker, M.; Guo, L.; Schoenebeck, F.; Rueping, M. Angew. Chem. Int. Ed. 2016, 55, 609. (e) Guo, L.; Hsiao, C.-C.; Yue, H.; Liu, X.; Rueping, M. ACS Catal. 2016, 6, 4438. (f) Guo, L.; Liu, X.; Baumann, C.; Rueping, M. Angew. Chem. Int. Ed. 2016, 55, 15415. (g) Fan, L.; Jia, J.; Hou, H.; Lefebvre, Q.; Rueping, M. Chem. Eur. J. 2016, 22, 16437. (h) Yue, H.; Guo, L.; Liu, X.; Rueping, M. Org. Lett. 2017, 19, 1788

(9) (a) Tobisu, M.; Chatani, N. Nickel-Catalyzed CrossCoupling Reactions of Unreactive Phenolic Electrophiles via $\mathrm{C}-\mathrm{O}$ Bond; Activation: Ni- and Fe-Based Cross-Coupling Reactions; Springer- International Publishing: Switzerland 2016. (b) Li, B.-J.; 
Yu, D.-G.; Sun, C.-L.; Shi, Z.-J. Chem. Eur. J. 2011, 17, 1728. (c) Tobisu, M.; Chatani, N. Acc. Chem. Res. 2015, 48, 1717.

(10) Application of alkenyl-nitriles, see (a) Wang, J.-P.; Nie, S.Z.; Zhou, Z.-Y.; Ye, J.-J.; Wen, J.-H.; Zhao, C.-Q. J. Org. Chem. 2016, 81, 7644. (b) Kim, S.; Kang, S.; Kim, G.; Lee, Y. J. Org. Chem. 2016, 81, 4048. (c) Müller, M.-A.; Pfaltz, A. Angew. Chem. Int. Ed. 2014, 53, 8668 .

(11) (a) Powell, K. J.; Han, L.-C.; Sharma, P.; Moses, J. E. Org. Lett. 2014, 16, 2158. (b) Li, L.-H.; Pan, Z.-L.; Duan, X.-H.; Liang, Y.-M. Synlett 2006, 2094. (c) Alterman, M.; Hallberg, A. J. Org. Chem. 2000, 65, 7984.

(12) Optimization, see Table $S_{1}$ in the Supporting Information.

(13) $\mathrm{Rh}$ and Pd-catalyzed decarbonylation of acyl cyanides, see: (a) Blum, J.; Oppenheimer, E.; Bergmann, E. D. J. Am. Chem. Soc. 1967, 89, 2338. (b) Murahashi, S.-I.; Naota, T.; Nakajima, N. J. Org. Chem. 1986, 51, 898.

(14) Optimization, see Table $S_{3}$ in the Supporting Information.

(15) Decarbonylation of acylphosphines for the synthesis of phosphines, see: Yu, R.; Chen, X.; Martin, S. F.; Wang, Z. Org. Lett. 2017, 19, 1808.

(16) (a) Morioka, T.; Nishizawa, A.; Furukawa, T.; Tobisu, M.; Chatani, N. J. Am. Chem. Soc. 2017, 139, 1416.

(17) Goossen, L. J.; Rodríguez, N.; Melzer, B.; Linder, C.; Deng G.; Levy, L. M. J. Am. Chem. Soc. 2007, 129, 4824. 


\section{Insert Table of Contents artwork here}

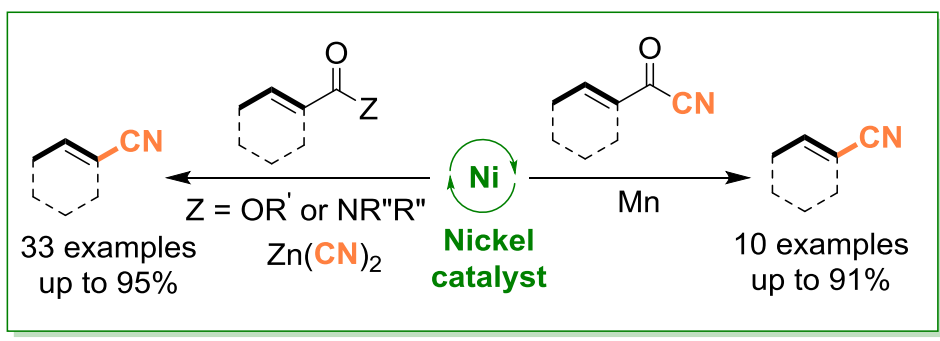

